\title{
Familial interstitial pulmonary fibrosis: A large family with atypical clinical features
}

\author{
Ranji Chibbar PhD MBBS FRCPC ${ }^{1}$, John A Gjevre MD FRCPC ${ }^{2}$, Francis Shih MD ${ }^{1}$, Heather Neufeld BSc ${ }^{1}$, \\ Edmond G Lemire MD PhD FRCPC ${ }^{3}$, Derek A Fladeland MD FRCPC ${ }^{4}$, Donald W CockCroft MD FRCPC ${ }^{2}$
}

R Chibbar, JA Gjevre, F Shih, et al. Familial interstitial pulmonary fibrosis: A large family with atypical clinical features. Can Respir J 2010;17(6):269-274.

\begin{abstract}
A large kindred of familial pulmonary fibrosis is reported. Six members from the first two generations of this particular kindred were described more than 40 years previously; six more individuals from the third and fourth generations have also been evaluated. The proband, now 23 years of age, has mild disease; the other 11 documented affected family members all died from their disease at an average age of 37 years (range 25 to 50 years). The pathology was that of usual interstitial pneumonia, as is typical in idiopathic pulmonary fibrosis. However, the initial radiographic pattern in many of these individuals was upper lobe and nodular and, along with the young age, was atypical for idiopathic pulmonary fibrosis. Several genetic abnormalities have been associated with familial pulmonary fibrosis. The present study examined the genes coding for surfactant protein-C, ATPbinding cassette protein $\mathrm{A} 3$ and telomerase, and found no abnormalities.
\end{abstract}

Key Words: ABCA3; Idiopathic pulmonary fibrosis; Familial pulmonary fibrosis; Surfactant protein-C; Telomerase; Usual interstitial pneumonia;

diopathic pulmonary fibrosis (IPF) is a progressive interstitial lung disease (ILD) generally affecting older individuals. Classically, there are diffuse peripheral and basilar-predominant reticular interstitial changes with a usual interstitial pneumonitis (UIP) pathology (1). Occasionally, IPF occurs in families and segregates in an autosomal dominant inheritance pattern (2). Familial IPF generally has clinical features similar to sporadic IPF (ie, older subjects, peripheral basal reticular ILD, UIP pathology and poor response to therapy) $(2,3)$. One or more genetic factors may be involved in the pathogenesis of familial $\operatorname{IPF}(1,4,5)$.

In 1966, Adelman et al (6) reported a large family in which six members were affected with IPF that proved fatal at a young age ( 35 to 50 years) (6). The affected members in two generations of this family (Figure 1) included the father (I-1, deceased at 50 years of age) and his three sons (II-2, II-3 and II-4, deceased at 43, 34 and 38 years of age, respectively). Two daughters (II-1 and II-7) also died of pulmonary fibrosis at 45 and 34 years of age, respectively. All three affected sons lived on to have children of their own, but neither of the two affected sisters bore any offspring.

In the past 25 years, at least six members of this family - five from the third generation (III-2, III-4, III-5, III-7 and III-11) and one from the fourth generation (IV-10) - have presented with pulmonary fibrosis (Figure 1). Four of these individuals were seen at the Royal University Hospital (Saskatoon, Saskatchewan),

\section{La fibrose pulmonaire interstitielle familiale : Une grande famille aux manifestations cliniques atypiques}

Les chercheurs rendent compte d'un grand groupe de personnes apparentées atteintes de fibrose pulmonaire familiale. Six membres des deux premières générations de ce groupe avaient été décrits plus de 40 ans auparavant. Six autres membres des troisième et quatrième générations avaient également été évalués. Le proposant, maintenant âgé de 23 ans, a une maladie bénigne. Les 11 autres membres de la famille documentée sont tous décédés de la maladie à un âge moyen de 37 ans (plage de 25 à 50 ans). On remarquait la pathologie habituelle de pneumonie interstitielle, classique en cas de fibrose pulmonaire idiopathique. Cependant, chez bon nombre de ces individus, le premier bilan radiographique indiquait une atteinte du lobe supérieur et nodulaire qui, conjointement au jeune âge, est atypique en cas de fibrose pulmonaire idiopathique. Plusieurs anomalies génétiques s'associent à la fibrose pulmonaire familiale. Dans la présente étude, les chercheurs ont examiné les gènes codant la protéine $\mathrm{C}$ du surfactant, la protéine cassette de liaison à l'ATP A3 et la télomérase et n'ont découvert aucune anomalie.

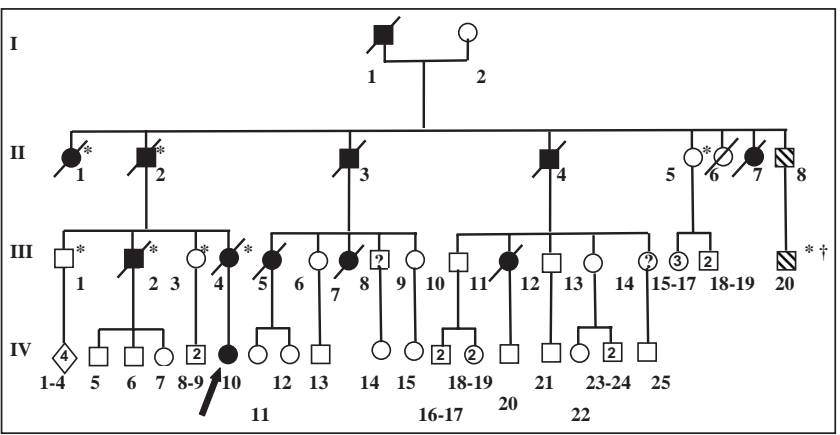

Figure 1) Family pedigree. Filled symbols denote affected individuals, symbols with hash marks indicate unconfirmed affected individuals and symbols containing a question mark indicate an unknown disease status. Squares represent males, circles represent females and diamonds represent multiple family members with sex not specified. The arrow indicates the proband. Slashes (/) denote deceased individuals. *Polydactyly; ${ }^{\dagger}$ Cleft lip and palate

while two were assessed elsewhere. The status of four family members is uncertain.

The present article reviews the clinical, radiographic and pathological pattern in these patients. Several genes known to be associated with IPF were analyzed; however, no pathogenic changes were identified.

${ }^{1}$ Department of Pathology, Department of Medicine, Division of Respirology; ${ }^{2}$ Critical Care and Sleep Medicine, Department of Pediatrics;

${ }^{3}$ Division of Medical Genetics; ${ }^{4}$ Department of Radiology, Royal University Hospital, University of Saskatchewan, Saskatoon, Saskatchewan

Correspondence: Dr Donald W Cockcroft, Division of Respirology, Critical Care and Sleep Medicine, Royal University Hospital, 103 Hospital

Drive, Ellis Hall, Room 551, Saskatoon, Saskatchewan S7N OW8. Telephone 306-966-8274 ext 2, fax 306-966-8694,

e-maildon.cockcroft@usask.ca 
TABLE 1

Radiographic and pathological features

\begin{tabular}{|c|c|c|c|c|}
\hline $\begin{array}{l}\text { Case } \\
\text { (Ref) }\end{array}$ & $\begin{array}{c}\text { Age at } \\
\text { death, years }\end{array}$ & Sex & $\begin{array}{l}\text { Radiology of interstitial } \\
\text { lung disease }\end{array}$ & Pathology \\
\hline $\mathrm{I}-1(6)$ & 50 & Male & $\begin{array}{l}\text { Peripheral upper lobe } \\
\text { predominant }\end{array}$ & NA \\
\hline II-1 (6) & 45 & Female & $\begin{array}{l}\text { Peripheral upper lobe } \\
\text { predominant }\end{array}$ & $\begin{array}{l}\text { Autopsy: } \\
\text { severe UIP* }\end{array}$ \\
\hline II-2 (6) & 43 & Male & Diffuse peripheral & NA \\
\hline II-3 (6) & 34 & Male & Upper lobe predominant & Bx: UIP* \\
\hline II-4 (6) & 38 & Male & Diffuse peripheral & NA \\
\hline II-7 (6) & 34 & Female & Diffuse peripheral & Bx: UIP* \\
\hline II-8 & Unknown & Male & $\dagger$ & NA \\
\hline III-2 & 36 & Male & Upper lobe reticular & Bx: UIP \\
\hline III-4 & 28 & Female & NA & Bx: UIP \\
\hline III-5 & 39 & Female & NA & Bx: UIP \\
\hline III-7 & 25 & Female & NA & $\begin{array}{l}\text { Bx: end-stage } \\
\text { fibrosis }\end{array}$ \\
\hline III-11 & 33 & Female & $\begin{array}{l}\text { Upper lobe nodular } \\
\text { peripheral }\end{array}$ & Bx: UIP \\
\hline III-20 & Unknown & Male & $\dagger$ & NA \\
\hline IV-10 & $23^{\ddagger}$ & Female & Mild upper lobe nodular & Bx: UIP \\
\hline
\end{tabular}

*Review of photographs in reference 6 ; ${ }^{\dagger}$ Family members report idiopathic

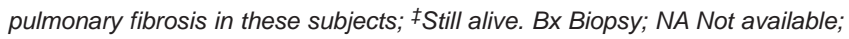
Ref Reference; UIP Usual interstitial pneumonitis

\section{Clinical features}

\section{METHODS}

The clinical, pathological and radiographic findings regarding the six additional cases from the later generations in this large kindred are presented. The additional studied cases are outlined briefly using the numbering system presented in the family pedigree (Figure 1).

\section{Genetic studies}

Ethics approval was obtained from the University of Saskatchewan Biomedical Ethics Research Board. Genomic DNA was obtained from blood leukocytes of the proband, 10 unaffected control subjects and 10 sporadic IPF cases. DNA from 11 family members (mostly unaffected), previously extracted in the 1980s, was kindly provided by Dr Elizabeth Ives of Memorial University (St John's, Newfoundland and Labrador). Paraffin-embedded lung tissue samples from three additional affected family members (III-2, III-4 and II-7) were available for DNA extraction.

Based on the published surfactant protein C (SP-C) gene sequence by Glasser et al (7), six primer pairs were designed and used in polymerase chain reaction (PCR) assays as described previously (8). The 30 coding exons of the ATPbinding cassette protein $A 3$ ( $A B C A 3$ ) gene of the proband were PCR amplified with flanking intronic primers derived from the published sequences reported by Brasch et al (9). DNA sequencing reactions of the purified fragments were performed (8). DNA sequencing of the proband for SP-C was also sent to The Johns Hopkins DNA Diagnostic Laboratory (Maryland, USA) for confirmation. Mutation analysis of telomerase TERT and TERC genes was performed by Ambry Genetics (California, USA).

A polymorphism detected at codon 186 of the SP-C gene was investigated using Hpy81 digestion of a PCR fragment spanning the region. The normal AGC codon is not digested by this restriction enzyme, whereas the presence of an AAC codon results in digestion.

\section{Clinical features}

\section{RESULTS}

The clinical features of the family members are summarized in Table 1. There was no evidence of consanguinity - a potential concern, particularly considering the high prevalence of affected individuals in generation II (Figure 1).

\section{IV-10 (proband)}

Presently, this woman is 23 years of age and is the daughter of III-4. Given the significant family history, she has been closely monitored for signs and symptoms of ILD. At 13 years of age, she had normal lung function, but presented clinically with allergies to house pets, which was confirmed on skin testing. She infrequently required salbutamol for mild asthma. A computed tomography (CT) lung scan was normal. She first presented with essentially no symptoms to an adult respiratory clinic at the Royal University Hospital in June 2005 at 19 years of age. Lung function at that time was normal except for a mild reduction in diffusing capacity. A chest radiograph was normal; however, a high-resolution CT scan of the chest revealed ILD that was predominantly nodular and mainly in the upper and mid-lung zones. An open lung biopsy in 2006 demonstrated a UIP pattern of pulmonary fibrosis. The patient remains asymptomatic (2009), with borderline low expiratory flow rates and lung volumes at approximately $80 \%$ of predicted, and a diffusing capacity of $64 \%$ of predicted.

\section{III-2}

This man was the son of the oldest affected brother (II-2) in the original family. He had been diagnosed with ILD elsewhere. He presented to the clinic in 1985 and, in that year, underwent an open lung biopsy showing a UIP pattern. This responded poorly to oral prednisone. His course was complicated by a spontaneous pneumothorax requiring chest tube drainage. He was accepted into a lung transplant program but deferred participation while he sought alternative therapy. He died at home in 1988 at 36 years of age. An autopsy revealed severe pulmonary fibrosis that had markedly progressed since the lung biopsy performed three years previously.

\section{III-4}

This 27-year-old female and sibling of III-2 was identified as having pulmonary fibrosis during her first and only pregnancy in 1986. A UIP pattern present on a lung biopsy performed later that year confirmed the diagnosis. She was treated with prednisone, but died of her disease before she was 28 years of age.

\section{III-5}

This woman was a paternal first cousin to both III-2 and III-4, and the daughter of the second affected son (II-3). She lived in another province and, in 1980, at 33 years of age, underwent an open lung biopsy that confirmed a diagnosis of pulmonary fibrosis. She died at 39 years of age.

\section{III-7}

This woman was a sibling of III-5 and died in 1977 at 25 years of age from progressive pulmonary fibrosis; an open lung biopsy performed two years earlier revealed severe fibrosis.

\section{III-11}

This woman was the daughter of the youngest affected son (II-4). She was followed at the Royal University Hospital between 1981 and 1987. She initially presented with markedly nodular 
interstitial pulmonary fibrosis, predominantly in the upper lobes. A lung biopsy performed in 1981 demonstrated interstitial fibrosis and bronchiolitis without evidence of any granulomata. This was believed to be consistent with UIP with some eosinophils. She was treated with prednisone and referred for lung transplant when the condition progressed. She died awaiting a lung transplant in 1987 at 33 years of age.

\section{Radiology}

Most of the results of the diagnostic imaging studies pertaining to this family have been lost over the years because the subjects died. However, high-quality studies on the proband (IV-10) are available. Some images and reports of previous radiographs and CT scans are available for some of the other subjects. IV-10 underwent recent radiographic and CT scans including highresolution images for evaluation. The radiographs demonstrated progressive mild to moderate volume loss over a six-year period. Small nodular opacities were also noted in the midzones bilaterally. These abnormalities strongly correlated with the CT findings of small perilymphatic nodules in the same mid to upper zone distribution (Figure 2). The nodules were primarily located in the interlobular septae and the subpleural/ fissural areas. There was no evidence of calcification or lymphadenopathy. The typical findings of IPF were absent with no reticulation or honeycombing, and with sparing of the peripheral and basal locations of the lungs. Similar radiographic features were also present in several of the other cases, with images or reports of primarily nodular disease that was more marked in the upper lobes. These features persisted over the course of follow-up imaging, although more diffuse disease eventually developed with some evidence of reticulation and honeycombing.

\section{Pathology}

Histopathological examination of a thoracoscopic lung biopsy from the proband (IV-10) revealed patchy interstitial fibrosis with associated fibroblastic foci, predominantly peribronchiolar, subpleural and paraseptal in distribution, and alternating with normal lung parenchyma. The fibroblastic foci were present at the edges of the dense scar and distinctly highlighted with Masson's trichrome stain (Figure 3). Slightly unusual features of this particular biopsy included a dominant chronic bronchiolitis comprised of a patchy peribronchiolar infiltrate rich in lymphocytes with foci of associated organizing pneumonia. Some of the patchy dense fibrosis with associated fibroblastic foci were also associated with bronchioles and had mild to moderate focal inflammatory infiltrate predominantly composed of polymorphic lymphocytes, scattered eosinophils and plasma cells. A few small lymphoid aggregates were also present in some of the peribronchiolar fibrotic foci. Adjacent alveoli were lined with type II pneumocytes. The intervening lung parenchyma was unremarkable in appearance except for a slight focal widening of interstitium with mild chronic inflammatory cells. These changes were focal and the majority of the pulmonary parenchyma was unremarkable. No honeycomb changes were seen. There was no marked eosinophilia and no granulomata were present.

Pathology reports of seven additional family members were available, with hematoxylin and eosin slides and corresponding blocks available from three of these patients. Reports (but no slides) were available for subjects II-3, II-7, III-5 and III-11. These open lung biopsies were performed in 1959, 1965, 1980 and 1981,
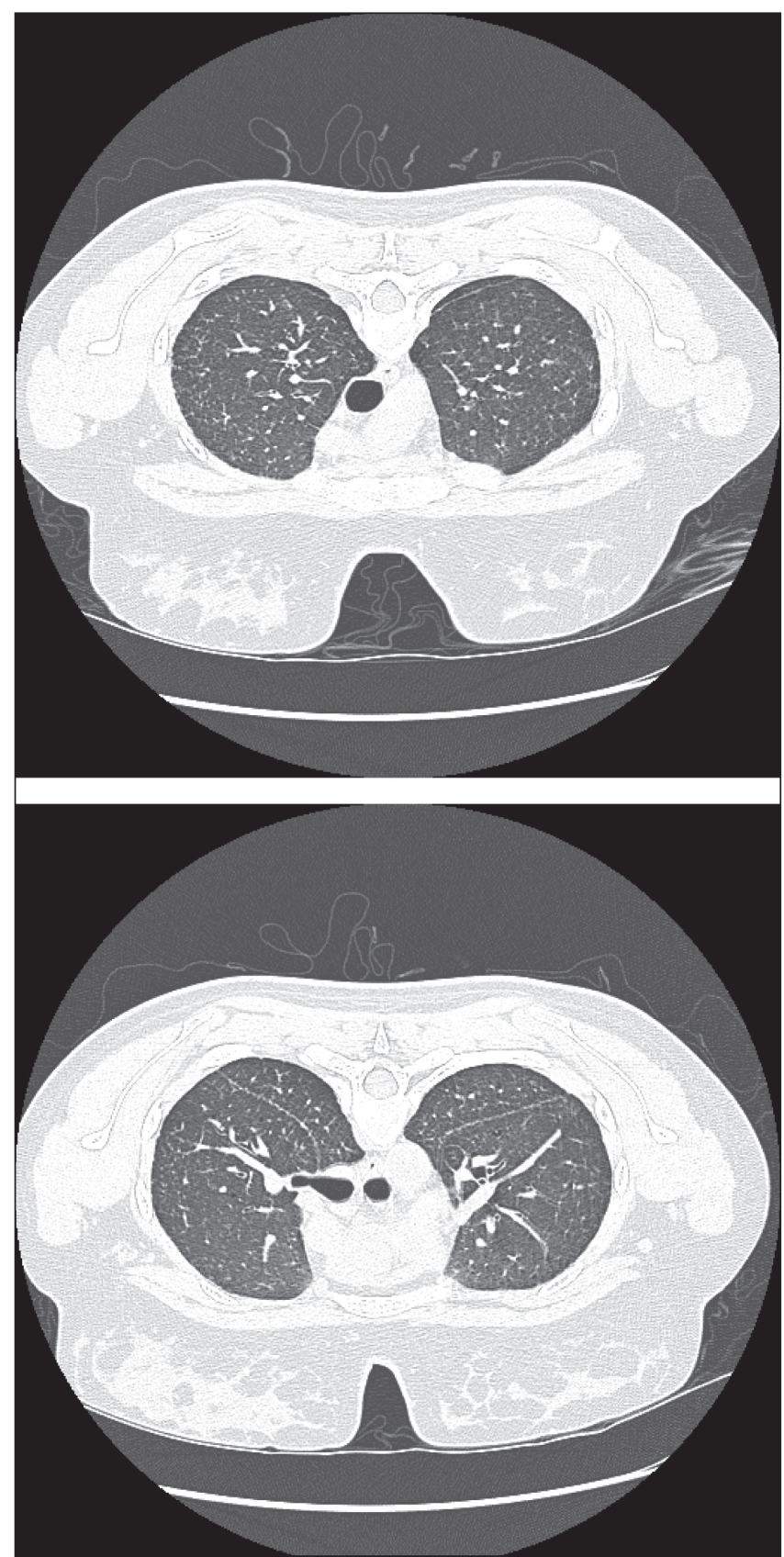

Figure 2) Subject IV-10. Prone, high-resolution computerized tomography scan images through the upper lung zones demonstrating small perilymphatic nodules that are predominantly septal in location (top), and perilymphatic nodules that are primarily in a subpleural location along the fissures (bottom)

at the ages of 35, 28, 33 and 27 years, respectively. The biopsies from 1959 (II-3) and 1965 (III-7) were given a diagnosis of familial fibrocystic pulmonary dysplasia (6). There were no diagnostic criteria at that time for what is currently known as UIP; however, the description of microscopic findings was typical of a UIP pattern of ILD. These biopsies represented an advanced stage of UIP compared with the proband who, at the time of biopsy, was asymptomatic and showed no honeycomb changes or extensive fibrosis. The biopsies from 1980 (III-5) and 1981 (III-11) were independently reviewed by external pulmonary pathologists. A diagnosis of 'UIP of unknown etiology' was rendered in both cases. 




Figure 3) Photomicrographs of hematoxylin and eosin- (left) and Masson's trichrome-stained (right) sections. Proband (IV-10): top; III-2: second; III-4: third; and III-7: bottom. All show the usual interstitial pneumonitis pattern with patchy fibrosis, intervening normal lung parenchyma and fibroblastic foci 
Reports and slides were both available from III-2, III-4 and III-7. These slides also showed a classic UIP pattern (Figure 3). These slides were reviewed along with the slides of other family members and the proband by external pulmonary pathologists. III-2 underwent an autopsy three years after his open biopsy and the slides prepared from lung tissue obtained at that time revealed a UIP pattern with honeycombing. The lung biopsy from III-4 (mother of the proband) showed a classic UIP pattern with predominant peribronchiolar lymphocytic infiltrate as noted in the proband. No granulomata, giant cells or Schaumann bodies were found in any of these specimens.

Tissue from the proband (IV-10) was submitted to electron microscopy analysis. Alveolar lining cells consisted of type I and type II pneumocytes. Some alveoli were lined with cuboidal type II pneumocytes. There was no significant decrease in the number of cytoplasmic lamellar bodies. No concentric lamellation or electron-dense bodies were identified. No abnormalities of cytoplasmic organelles were seen. No electron microscopy studies were performed on biopsy samples from other family members.

\section{Genetic studies}

No significant genetic abnormalities were found in the analysis of the SP-C, ABCA or telomerase genes.

Alignment of the SP-C gene sequences obtained from the proband with the published SP-C sequence (7) revealed a heterozygous base pair change at position 413 of exon 4 . Whereas the control sequence showed a $\mathrm{C}$, the index case showed a $\mathrm{C} / \mathrm{A}$ double peak, which resulted in a threonine to asparagine substitution at amino acid position 138 of the SP-C proprotein. Also found were a heterozygous $\mathrm{G} / \mathrm{C}$ located at nucleotide position 438 (a result that caused no amino acid change), while a heterozygous $\mathrm{G} / \mathrm{A}$ at nucleotide position 557 (amino acid 186) produced a serine to asparagine substitution.

One of the IPF-affected relatives of the index case showed the same heterozygous polymorphism as the index case at position 413 of exon 4 . The other five affected members of the kindred and all nine unaffected family members did not show a single nucleotide polymorphism at position 413. No polymorphism at nucleotide position 557 was identified in any of the cases. Thus, the two heterozygous mutations in the SP-C gene resulting in amino acid changes for the index case could not be associated with the IPF in this family.

Analysis of the SP-C gene from 10 sporadic IPF patients did not reveal any of the previously known mutations of the SP-C gene. However, polymorphisms at nucleotide 557 (amino acid 186) and nucleotide 413 (amino acid 138) were noted. Three of the 10 sporadic IPF cases were heterozygous at amino acid 186. The same cases had the T138N single-nucleotide polymorphism, with two being heterozygous.

The polymorphism at amino acid position 186 was analyzed by digesting PCR-amplified gene products with the restriction enzyme Hpy81. The digestion revealed a normal SP-C sequence in 12 of the 19 cases, whereas three cases demonstrated a homozygous polymorphism in the codon for amino acid 186. In four cases, a heterozygous pattern was observed.

The ABCA3 gene, which is known to be involved in surfactant secretion, was subsequently analyzed for evidence of any pathogenic mutations. On alignment, introns 5, 10 and 14 showed $G$ to A, $C$ to $T$, and $A$ to $G$ transversions, respectively. A $G$ to $A$ transversion in the forward direction was identified in exon 18 .
This change was not seen in the reverse direction. This change was noted at nucleotide position 31,780 , resulting in an amino acid substitution at position 801 to glutamic acid from lysine and, hence, altering the charge. This is present in the area of NBD-1, which is conserved through different species. However, this was repeated several times, including using DNA from other family members and normal controls with the same results. After several repeat experiments, it was concluded to be of no significance.

Full genetic analysis of the telomerase TERT and TERC genes from DNA of the proband was performed and no mutations were identified.

\section{DISCUSSION}

The original report of this particular family was published more than 40 years previously (6), before modern classification of the clinical radiographic and pathological features of the idiopathic interstitial pneumonias $(10,11)$. Data are presented for six additional subjects from the third and fourth generation of this large kindred. While the pathology is that of UIP, typical for IPF, the clinical and radiographic features are atypical. IPF, sporadic or familial, is usually a disease affecting older individuals and is associated with radiographically diffuse peripheral basal-predominant reticular interstitial changes (11). In the appropriate clinical setting, typical findings on high-resolution CT scan are able to confirm a diagnosis in $50 \%$ or more of individuals (11).

The family members consistently demonstrated clinical and radiographical features atypical of IPF. These subjects were considerably younger, the oldest reported died at 50 years of age and the average age at death of the 11 members with documented disease was approximately 37 years. The radiographical features, particularly initially, were more upper lobe and more nodular than that seen in IPF. The radiographic pattern was initially suggestive of sarcoidosis in subjects III-11 and IV-10.

In addition to the atypical clinical and radiographic features, the pathology in the proband and her mother showed minor unusual features including some bronchiolitis with foci of organizing pneumonia. The remainder of the reviewed family members showed classic UIP (10). The upper lobe predominance, bronchiolitis and organizing pneumonia raised the possibility of chronic hypersensitivity pneumonitis (CHP). However, there was no clinical or serological evidence to support hypersensitivity pneumonitis in our patients. These individuals all had classic UIP pathology features (10), with none of the features (granulomata, Schaumann bodies and giant cells) seen in CHP. We are not aware of reports of CHP in multiple family members. The aggressive clinical course was also atypical of CHP. In addition, there was no evidence supporting alternative causes of UIP most notably, rheumatoid arthritis or asbestosis.

One explanation for these unusual histological findings in the biopsy of the index case and her mother is that peribronchiolar injury and inflammation may be an early phenomenon of UIP. Most of the biopsies in UIP patients are performed at a very late stage (as in some of the family members in our study). There are no known definitive histological features of early IPF reported in the literature. It is possible that IPF starts with a peribronchiolar inflammatory process, with inflammation not usually excessive in advanced disease. 
The pathogenesis of IPF is very complex and may involve endogenous or exogenous repetitive injury to alveolar epithelial cells over time, ultimately leading to fibrosis. Study of familial IPF cases is important to identify the primary genetic abnormality. In the past several years, investigators have attempted to identify the cellular/molecular abnormalities in cases of familial IPF. Two of the genes with mutations in familial IPF (SP-C and $A B C A 3$ ) involve abnormalities of surfactant synthesis or secretion, and the third gene affects the survival of alveolar epithelial cells due to shortened telomeres because of defects in the telomerase TERT and/or TERC genes.

Mutations in the SP-C gene have been identified in several UIP kindred (12-14). Previously, we reported (8) a heterozygous mutation in exon 5 of the SP-C gene in one of our IPF kindreds. However, in the present study, no specific mutation of the SP-C gene was identified. Of all the studies investigating familial and sporadic IPF, it appears that mutations in the SP-C gene in familial IPF are an infrequent event and, to date, no definite SP-C mutation in sporadic IPF cases has been identified (15).

Recently, mutations in the $A B C A 3$ gene were identified in neonates with fatal surfactant deficiency (16-18). ABCA3 is highly expressed in the lung and has been localized to the limiting membrane of lamellar bodies, and is involved in surfactant metabolism. A deficiency of ABCA3 leads to decreased phosphatidylcholine and phosphatidylglycerol in surfactant and dysgenesis of lamellar bodies (19). Mutations in the $A B C A 3$ gene have been detected in approximately $8 \%$ to $10 \%$ of familial cases, especially children and young adults. Most of these young adult patients experienced upper lobe-predominant fibrotic changes. Our proband was 19 years of age at the time of biopsy and most of the family members died of IPF at a young age; therefore, it was decided to sequence the $A B C A 3$ gene. No

\section{REFERENCES}

1. American Thoracic Society. Idiopathic pulmonary fibrosis: Diagnosis and treatment. International Consensus Statement. Am J Respir Crit Care Med 2000;161:646-64.

2. Lee HL, Ryu JH, Wittmer MH, et al. Familial idiopathic pulmonary fibrosis: Clinical features and outcome. Chest 2005;127:2034-41.

3. Rosas IO, Ren P, Avila NA, et al. Early interstitial lung disease in familial pulmonary fibrosis. Am J Respir Crit Care Med 2007;176:698-705.

4. Wang Y, Kuan PJ, Xing C, et al. Genetic defects in surfactant protein A2 are associated with pulmonary fibrosis and lung cancer. Am J Hum Genet 2009;84:52-9.

5. Cronkhite JT, Xing C, Raghu G, et al. Telomere shortening in familial and sporadic pulmonary fibrosis. Am J Respir Crit Care Med 2008;178:729-37.

6. Adelman AG, Chertkow G, Hayton RC. Familial fibrocystic dysplasia: A detailed family study. CMAJ 1966;95:603-10.

7. Glasser SW, Korfhagen TR, Bruno MD, Dey C, Whitsett JA. Structure and expression of the pulmonary surfactant protein SP-C gene in the mouse. J Biol Chem 1990;265:21986-91.

8. Chibbar R, Shih F, Baga M, et al. Nonspecific interstitial pneumonia and usual interstitial pneumonia with mutation in surfactant protein $\mathrm{C}$ in familial pulmonary fibrosis. Mod Pathol 2004;17:973-80.

9. Brasch F, Schimanski S, Mühlfeld C, et al. Alteration of the pulmonary surfactant system in full-term infants with hereditary ABCA3 deficiency. Am J Respir Crit Care Med 2006;174:571-80.

10. Leslie KO. Historical perspective: A pathologic approach to the classification of idiopathic interstitial pneumonias. Chest 2005;128:513S-19S.

11. Souza CA, Müller NL, Flint J, Wright JL, Churg A. Idiopathic pulmonary fibrosis: Spectrum of high-resolution CT findings. Am J Roentgenol 2005;185:1531-9. exonic mutations, splice-site mutations or polymorphisms in the 30 exons of the $A B C A 3$ gene were found.

Mutations in telomerase genes have accounted for $8 \%$ to $15 \%$ of reported familial IPF cases. Telomerase has two essential components: hTERT - the catalytic reverse transcriptase and - hTR - an RNA component that provides the template for nucleotide addition. Mutations in hTERT or hTR cause haploinsufficiency leading to accelerated telomere shortening and cell death. Several studies $(20,21)$ have identified mutations predominantly in the $h T E R T$ gene and a rare mutation in the hTR gene in some cases of familial IPF. Shortened telomeres damage DNA and lead to apoptosis. According to this hypothesis, the primary defect in IPF is the loss of alveolar epithelial cells. However, in our index case, no mutations in either the $h T E R T$ or $h T R$ gene were identified.

IPF is an aggressive form of chronic, progressive interstitial fibrosis for which the exact etiology remains elusive. The development of IPF is a complex process and likely to involve multiple genes that each contribute to the pathogenesis of and predisposition to IPF. More research needs to be performed on these genetic links to, hopefully, identify etiological factors and improve our understanding of this disease and, hence, facilitate treatment of this particular type of pulmonary fibrosis. These types of studies may also help to identify susceptible individuals prone to develop UIP later in life.

\section{SUMMARY}

We reported on a large kindred with clinically and radiologically atypical familial IPF, and were unable to identify genetic abnormalities in three genes purported to be associated with familial IPF.

ACKNOWLEDGEMENTS: The authors thank Beth Davis and Jacquie Bramley for assisting in the preparation of the manuscript.

12. Nogee LM, Dunbar AE III, Wert SE, et al. A mutation in the surfactant protein $\mathrm{C}$ gene associated with familial interstitial lung disease. N Engl J Med 2001;344:573-9.

13. Nogee LM, Dunbar AE III, Wert S, et al. Mutations in the surfactant protein $\mathrm{C}$ gene associated with interstitial lung disease. Chest 2002;121:20S-21S.

14. Thomas AQ, Lane K, Phillips J III, et al. Heterozygosity for a surfactant protein $\mathrm{C}$ gene mutation associated with usual interstitial pneumonitis and cellular nonspecific interstitial pneumonitis in one kindred. Am J Respir Crit Care Med 2002;165:1201-2.

15. Markart P, Ruppert C, Wygrecka M, et al. Surfactant protein C mutations in sporadic forms of idiopathic interstitial pneumonias. Eur Respir J 2007;29:134-7.

16. Shulenin S, Nogee LM, Annilo T, et al. ABCA3 gene mutations in newborns with fatal surfactant deficiency. N Engl J Med 2004;350:1296-303.

17. Saugstad OD, Hansen TW, Rønnestad A, et al. Novel mutations in the gene encoding ATP binding cassette protein member A3 (ABCA3) resulting in fatal neonatal lung disease. Acta Paediatr 2007;96:185-90.

18. Young LR, Nogee LM, Barnett B, et al. Usual interstitial pneumonia in an adolescent with $A B C A 3$ mutations. Chest 2008;134:192-5.

19. Ban N, Matsumura Y, Sakai H, et al. ABCA3 as a lipid transporter in pulmonary surfactant biogenesis. J Biol Chem 2007;282:9628-34.

20. Armanios MY, Chen JJ, Cogan JD, et al. Telomerase mutations in families with idiopathic pulmonary fibrosis. N Engl J Med 2007;356:1317-26.

21. Tsakiri KD, Cronkhite JT, Kuan PJ, et al. Adult-onset pulmonary fibrosis caused by mutations in telomerase. Proc Natl Acad Sci U S A 2007;104:7552-7. 


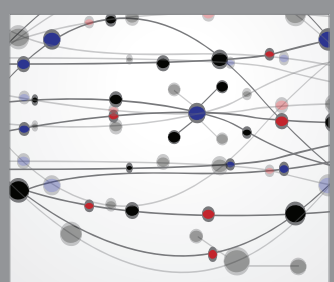

The Scientific World Journal
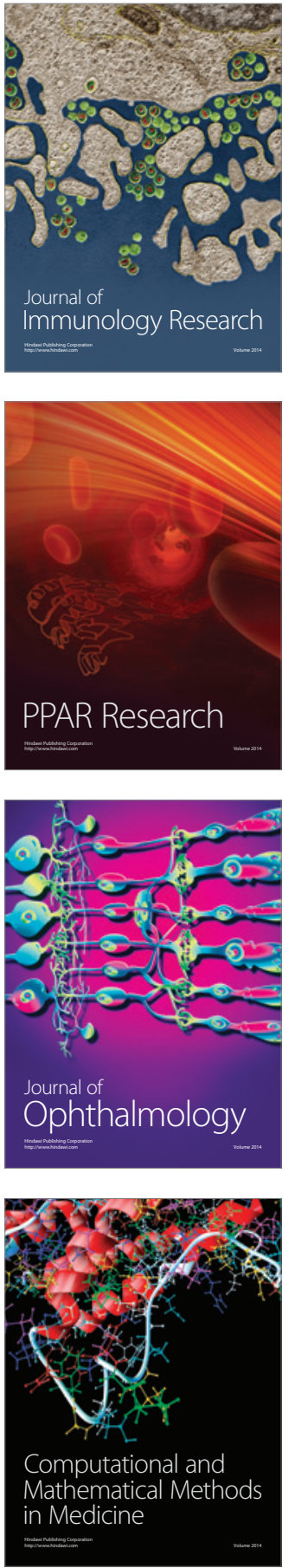

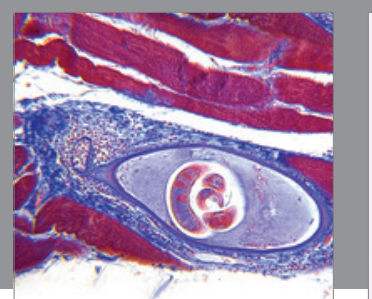

Gastroenterology Research and Practice

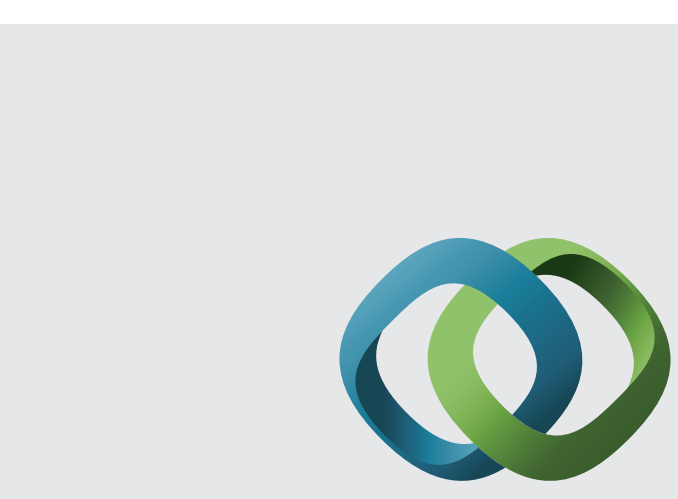

\section{Hindawi}

Submit your manuscripts at

http://www.hindawi.com
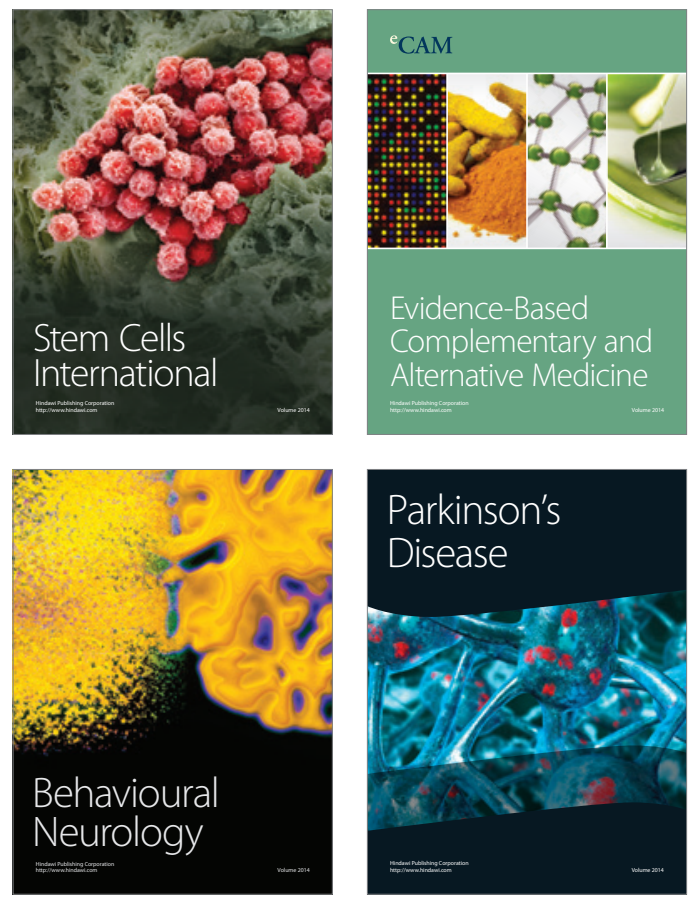
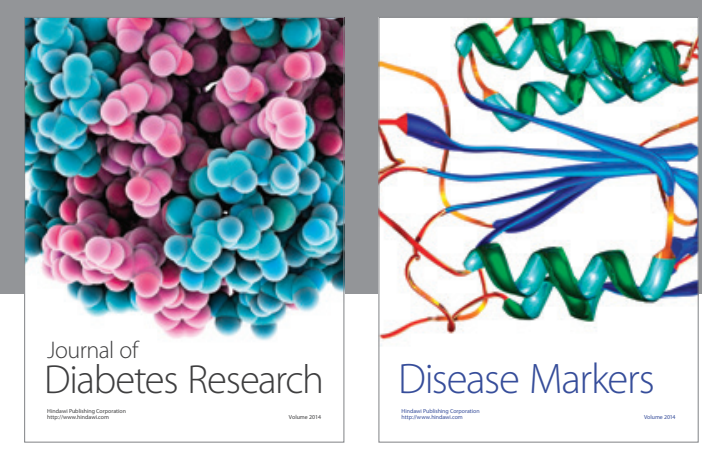

Disease Markers
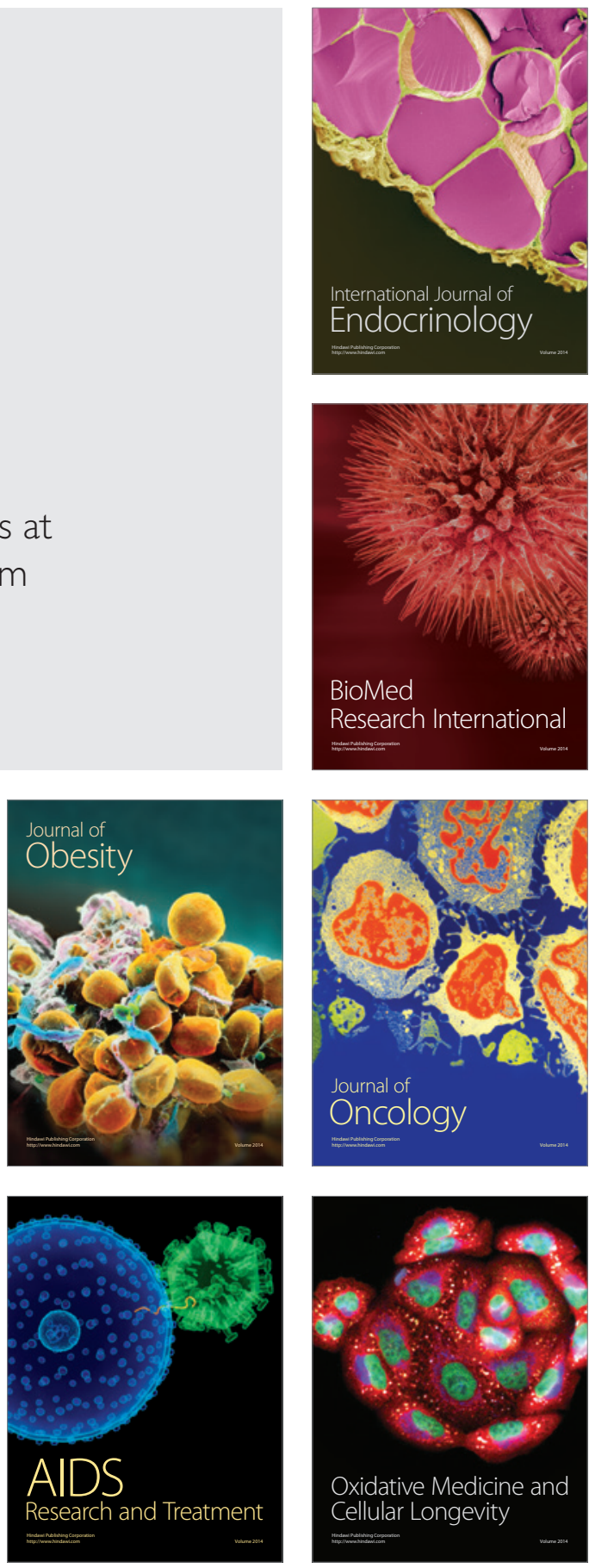